\title{
Current Applicable DNA Markers for Marker Assisted Breeding in Abiotic and Biotic Stress Tolerance in Rice (Oryza sativa L.)
}

\author{
Franz Marielle Nogoy ${ }^{1}$, Jae-Young Song ${ }^{1}$, Sothea Ouk ${ }^{1}$, Shadi Rahimi ${ }^{1}$, Soon Wook Kwon ${ }^{2}$, Kwon-Kyoo Kang ${ }^{3}$, \\ Yong-Gu Cho* \\ ${ }^{1}$ Department of Crop Science, Chungbuk National University, Cheongju 28644, Korea \\ ${ }^{2}$ Department of Plant Bioscience, Busan National University, Busan 50463, Korea \\ ${ }^{3}$ Department of Horticultural Life Science, Hankyong National University, Anseong 17579, Korea
}

\begin{abstract}
Abiotic and biotic stresses adversely affect rice (Oryza sativa L.) growth and yield. Conventional breeding is a very effective method to develop tolerant rice variety; however, it takes a decade long to establish a new rice variety. DNA-based markers have a huge potential to improve the efficiency and precision of conventional plant breeding via marker-assisted selection (MAS). The large number of quantitative trait loci (QTLs) mapping studies for rice has provided an abundance of DNA marker-trait associations. The limitations of conventional breeding such as linkage drag and lengthy time consumption can be overcome by utilizing DNA markers in plant breeding. The major applications of DNA markers such as MAS, QTL mapping and gene pyramiding have been surveyed. In this review, we presented the latest markers available for some of the most important abiotic and biotic stresses in rice breeding programs. Achieving a significant impact on crop improvement by marker assisted breeding (MAB) represents the great challenge for agricultural scientists in the next few decades.
\end{abstract}

Keywords Marker-assisted selection, Marker assisted breeding, Abiotic stress, Biotic stress, Rice, Resistant, Climate change

\section{INTRODUCTION}

Climate change is causing huge effects in all living creatures on earth. Few decades ago, scientists have proven that rising greenhouse gas emissions caused by the use of fossil fuels and industries lead to higher temperatures (Harvey 2015). Last year, the United Nations (U.N.) Climate Change Conference in Paris was able to come up with an agreement for a global climate effort. One of the key outcomes of the conference is to reaffirm the goal of limiting global temperature increase well below $2^{\circ} \mathrm{C}$, while urging efforts to limit the increase to $1.5^{\circ} \mathrm{C}$ (Outcomes of the U.N. Climate Change Conference in Paris 2015). Climate change, increasing world population and food security all together requires rice scientists to address these issues in their respective researches.

Rice (Oryza sativa L.) is one of the most important food crops in the world and maintaining stable rice production is extremely important to feed the constantly growing human population in changing climate (Sasaki and Burr 2000; Maclean et al. 2002). Rice has been exposed to many environmental stresses. There are two broad areas of environmental stresses, abiotic (salinity, heat, drought, cold, submergence, radiation, and heavy metals) and biotic (pathogens and herbivore) factors (Gomez 2013). Environmental stresses such as heat, cold, drought, and salinity factors have extremely affected on average yield losses in world agriculture (Wang et al. 2003). Among these stresses, the single most common limiting abiotic stress is low water supply simply described as drought (Tester and Bacic 2005). Heat stress is one of the environmental stresses that limits biomass productivity and grain production of crops (Boyer 1982). Other significant abiotic stresses limiting growth of both forage grasses and cereals are salinity and acidity, next to these is low temperature (Tester and Bacic 2005). Furthermore, there

Received August 17, 2016; Revised August 22, 2016; Accepted August 23, 2016; Published August 31, 2016

*Corresponding author Yong-Gu Cho, ygcho@cbnu.ac.kr, Tel: +82-43-261-2514, Fax: +82-43-273-2242 
was a huge impact on plants by biotic stresses such as pests and pathogens. Among biotic stresses, three diseases have been considered to be the most devastating worldwide in rice, bacterial blight caused by Xanthomonas oryzae pv. oryzae, blast by Pyricularia grisea, and sheath blight by Rhizoctonia solani. Similarly, three groups of insects, stemborers (yellow stemborer Tryporyza incertulas and striped stemborer Chilo suppressalis), leaffolders (Marasmia patnalis and Cnaphalocrocis medinalis), and planthoppers (mostly brown planthopper [BPH], Nilaparvata lugens), have been the most damaging pests (Jiang et al. 2012). In addition, infestation of white-backed planthopper (WBPH), Sogatella furcifera (Horvath) which is a phloem sucking insect of rice has affected rice growth and productivity.

Development of the disease-resistant or stress-tolerant plant is an important objective in rice breeding programs, because the production of rice can be constantly interfered by several major abiotic and biotic stresses. Rice and other crops have their own mechanisms to tolerate stress and there are many uncovered defense mechanisms at molecular level. The knowledge of physiology and molecular biology of stress tolerance in rice are helpful for the biotechnological improvement of rice productivity (Gomez 2013). One useful biotechnological tool that was developed throughout the years is DNA-based markers. From conventional breeding that takes place around 10 years to select a stable and desirable phenotype to marker-assisted selection (MAS), genetic functional markers were able to shorten rice varietal development. Another use of DNA-based markers is overcoming the barrier of "linkage drag" which refers to the presence of undesirable genes in the chromosomal region of the target gene thereby making it difficult to avoid such traits when using conventional breeding (Kottearachchi 2013). Also, economic analysis has shown the potential impacts of utilizing marker assisted breeding (MAB) by overcoming drawbacks of conventional breeding in rice that ultimately reduce the cost of production and promote economic growth (Kottearachchi 2013).

For this review, we present the recent DNA-based markers for some of the most significant abiotic and biotic stress tolerant genes and for MAS application in rice breeding programs like screening resistant plants from a germplasm and genotyping breeding populations. These markers are proven to work from different studies published recently from germplasm screening, results of fine mapping and gene pyramiding methods.

\section{DNA-BASED MOLECULAR MARKERS}

DNA markers are defined as a fragment of DNA revealing changes in sequences, which can be used to detect polymorphism between different genotypes or alleles of a gene for a particular sequence of DNA in a population or gene pool (Andersen 2013). DNA marker is a small region of DNA sequence showing polymorphism (base deletion, insertion, and substitution) between different individuals (Andersen 2013). It is a part of the gene itself to be representative of the phenotypic traits and/or a fragment of flanking regions, which is located very close to the candidate gene, and are also considered useful tools that can be indirectly displaying the variable phenotypic traits. There are two basic methods to detect the polymorphism: southern blotting and polymerase chain reaction (PCR). Mohler and Singrün (2004) gave three key issues for an effective molecular marker in MAS: i) markers should co-segregate or map as close as possible to the target gene (within $2 \mathrm{cM}$ ), in order to have low recombination frequency between the target gene and the marker, ii) for unlimited use in MAS, markers should display polymorphism between genotypes with and without the target gene, iii) cost-effective, simple PCR markers are needed to confirm genotyping efficiency for the rapid screening of large populations. Lateef (2015) simplified the different marker systems based on generation development. The first and low-throughput marker system is restriction fragment length polymorphisms (RFLPs), medium-throughput marker systems include random amplified polymorphic DNAs (RAPDs), simple sequence repeats (SSRs), and amplified fragment length polymorphisms (AFLPs) while the latest generation is the high-throughput marker system comprised of single nucleotide polymorphisms (SNPs), KBioscience Competitive Allele-Specific PCR (KASpar), and genotyping by sequencing (GBS). Based on various MAS breeding approaches, RFLPs are the best marker type 
for many purposes, but are low throughput technology and have high cost of genotyping. Therefore, PCR-based markers like RAPDs and AFLPs are faster and cheaper, and can also be applied in genetic diversity and gene mapping, however, their limiting factors are lack of reproducibility and specificity (Lateef 2015). With the availability of rice whole genome sequence and re-sequencing data, SNPs are exhorted in construction of high resolution genetic maps, investigation of population evolutionary history and discovery of marker-trait associations. The use of SNPs is further exemplified in KASPar assay, which is the patented SNP genotyping system from KBioscience based on fluorescent resonance energy transfer (FRET) (Robinson and Holme 2011). It allows detection of SNPs without a separation step coupled with the use of competitive allele specific PCR, thus, the KASP system offers a superior system for determination of SNP or insertion/deletion genotypes (Robinson and Holme 2011). As different kinds of markers were described above, each kind can be more advantageous to one breeding design and less valuable to another breeding method.

Conventional plant breeding has depended on phenotypic factors for the selection/confirmation of agronomic traits. MAB approaches to conventional breeding substantially has reduced the plant breeding cycles and increased the precision and efficiency of new cultivar development in plant breeding programs (Ribaut and Hoisington 1998; Morris et al. 2003).

\section{ABIOTIC STRESSES}

\section{Drought}

Water is the carrier of nutrients and minerals from soil through roots to all parts of the plant for distribution, aside from the transport of biomolecules. Drought is one of the most common stresses that impact growth and development of plants under water-limiting environments. The drought tolerance of plants can be divided into following various types including drought avoidance, escape, recovery, and dehydration tolerance (Kramer and Boyer 1995). Drought avoidance includes root depth, which can absorb available water in deep soil and dehydration tolerance consists of plant's capability such as drought recovery and growing again (Salekdeh et al. 2002). As drought mainly occurs in upland, selection for a well-developed root system with long and thick roots should improve the drought tolerance of upland rice because the plant will be able to absorb stored water in the deep soil layers. Phenotypic selection for root morphological traits in conventional breeding programs is impractical. The use of molecular markers could provide a useful tool to support phenotypic selection. Several mapped populations were developed to detect quantitative trait locus (QTLs) influencing root morphology and other drought-related traits that could be used in MAS to improve upland varieties. Uga et al. (2011) detected a new major QTL controlling ratio of deep rooting (RDR) on chromosome 9 by using 117 recombinant inbred lines (RILs) between lowland cultivar IR64 and upland cultivar Kinandang Patong (KP). The RDR QTL Dro1 (deeper rooting 1) was mapped within 1 cM between RM24393 and RM7424. They suggested Drol QTL, which is associated with root growth angles, would be useful for detecting an increased deep rooting trait under limited water conditions. In a report by Lang and Buu (2008), they worked on the mapping and MAS of major genes for drought stress in rice, they found out drought tolerance in the region that indicated the occurrence of recombination between segments derived from 329 plants of $\mathrm{BC}_{2} \mathrm{~F}_{2}$ from OM1490/WAB880-1-3818-20-P1-HB. Twenty markers were used to genotype the $329 \mathrm{BC}_{2} \mathrm{~F}_{2}$ plants. SSR markers located at the drought recovery score (DRS) genes between RM201 $(0.4 \mathrm{cM})$ and RM328 (13.8 cM) on chromosome 9 (Lang and Buu 2008). The target segment on chromosome 9 (RM201) significantly related to increase root length and drought tolerance under drought stress treatment (Lang and Buu 2008). Another SSR marker that can be used for MAS is RM8085, it is the only marker that showed complete co-segregation among individual RILs. RM8085 was mapped on chromosome 1 at $139.9 \mathrm{cM}$ and is linked to leaf rolling and leaf drying under drought stress (Salunkhe et al. 2011). Shamsudin et al. (2016) used three drought yield QTLs, $q D T Y_{2.2}, q D T Y_{3.1}$, and $q D T Y_{12.1}$ with consistent effect on grain yield under reproductive stage drought stress in gene pyramiding work for an elite Malaysian rice 
cultivar. These three QTLs have effectively worked in foreground selection in each of their breeding generation. The markers mentioned above can be applied in QTLs related to DRS, leaf rolling, leaf drying and drought yield.

\section{Salinity}

Soil salinity is an increasing limiting factor in rice growing areas. The precise effect of salinity on the rice harvest is determined by a complex interaction of various factors including the severity, timing, and duration of the stress (Thitisaksakul et al. 2015). Salinity tolerance at seedling, vegetative, flowering and ripening stages of rice seems to be managed by independent genes (Linh et al. 2012). Saltol is a major QTL and was identified in the salt-tolerant cultivar Pokkali. Its location was found on chromosome 1. This QTL confers salinity tolerance at the vegetative stage and explains from $64 \%$ to $80 \%$ of the phenotypic variance (Linh et al. 2012). The SSR marker, RM8094 found in Saltol is considered to be superior for analysis of genetic diversity (Nejad et al. 2008). Rice genotypes with the Pokkali band type for locus RM8094 marker were either highly tolerant or tolerant to salinity stress at the seedling stage (Nejad et al. 2008). Aside from RM8094, some of salt-tolerant genotypes had the Pokkali marker allele for RM10745 as well. Nejad et al. (2008) have proven in their results that RM8094 and RM10745 are useful for MAS of Saltol QTL. In a more recent study, three sequence tagged site (STS) markers were presented for MAS, from the genome sequences of SKCl, SalT, and DST. STS markers were developed based on Insertion/Deletions (InDels) between Nipponbare and 9,311 genome sequences of the previously mentioned gene names. STS markers, Wn1 1463 and Wn11466, were designed based on $4 \mathrm{bp}$ and $17 \mathrm{bp}$ InDels downstream of SKC1 (LOC_Os01g20160); Wn13900 was based on a 4 bp InDel upstream of SalT (LOC_Os01g24710); Wn13902 and Wn13903 were based on 7 bp and 8 bp InDels in the SalT coding region; Th32637 was based on a 3 bp InDel upstream in DST (LOC_Os03g57240); and Th32638 and Th32369 were based on 12 bp and 18 bp InDels in the coding region of DST (Emon et al. 2015). There were some efforts towards breeding salinity tolerance in plant via MAS (Ashraf et al. 2012) for the development of salt tolerant cultivars. It is expected that the utility of MAS for breeding of salinity tolerance traits will be increased.

\section{Chilling stress}

Rice is commonly grown in tropical areas, thus it is more sensitive to low temperature. The optimum temperature for seed germination and early seedling growth is from $25^{\circ} \mathrm{C}$ to $35^{\circ} \mathrm{C}$ (de los Reyes et al. 2003). Chilling stress affects rice growth throughout its development from germination until harvest. Hence, development of chilling stress tolerant cultivar is a common breeding goal. And of course, to aid fast and effective selection of lines with chilling stress tolerance, MAS is a useful and precise strategy. In a review done by Zhang et al. (2014), they summarized various QTLs related to chilling tolerance at different growth stages. Here, we'll simply present the markers that can be directly used for MAB. In one research work, a RIL population derived from a japonica/indica cross was assessed for chilling tolerance at early seedling stage at $10^{\circ} \mathrm{C}$. Main-effect QTL for the trait was mapped via composite interval mapping using a linkage map with 198 marker loci. The group was able to identify four putative QTLs for the trait, which were mapped on chromosomes 1, 3, 7, and 11. Among these QTL, qSCT-11 showed a large additive effect on the trait, explaining $26 \%$ to $30 \%$ of the phenotypic variation in the treatment of 13 days at $10^{\circ} \mathrm{C}$ with a LOD of 16-19. This QTL was closely linked to SSR marker RM202 and its positive allele came from the parent Lemont (Chen and Li 2005). This allele would be useful for the improvement of rice chilling tolerance through MAS. There are also molecular markers associated with chilling response related phenotypes, like, membrane integrity, photoinhibition and visual assessment of damage (Bonnecarrère et al. 2014). SSR marker RM22034 is associated with membrane integrity, RM6547 and RM14978 with photoinhibition, and RM144 with visual assessment of damage (Bonnecarrère et al. 2014). All the markers are currently available for marker assisted selection in rice breeding programs located in temperate regions (Bonnecarrère et al. 2014). Three more QTLs, qPSST-3, qPSST-7, and qPSST-9 were verified from ten chilling-tolerant lines with spikelet fertility (SF) of $51 \%$ to 
$81 \%$ compared to $7 \%$ (chilling-sensitive parent) and $73 \%$ (chilling-tolerant donor) (Jena et al. 2012).

\section{Heat}

The year 2016 is the hottest year to date. The temperature recorded in the month of June across global land and ocean surfaces was $1.62^{\circ} \mathrm{F}\left(0.90^{\circ} \mathrm{C}\right)$ higher than the 20th century average of $59.9^{\circ} \mathrm{F}\left(15.5^{\circ} \mathrm{C}\right)$. This was the highest for June in the 1880-2016 record (Climate Central 2016). Heat stress is one of the growing major factors that affect crop productivity negatively. High temperature is detrimental to both the vegetative and reproductive stages of rice (Pareek et al. 1995). In rice, once the temperature goes $5^{\circ} \mathrm{C}$ higher than the threshold level at flowering stage, it can induce floret sterility thereby affecting yield losses with maximum yield loss up to $80 \%$ (Ahmad et al. 2014). Through molecular breeding strategy, studies have been carried out to create molecular map of heat tolerance QTLs at booting, flowering, grain filling, and ripening stages in rice. In different rice population used by Ye et al. (2015), they identified QTL qHTSF4.1 consistently present across different genetic backgrounds (IR64/Giza178 and IR64/N22 populations; three-way-cross population IR64//Milyang23/Giza178; $\mathrm{BC}_{5} \mathrm{~F}_{2}$ population with clean background of IR64) and solely mentioned that it could be an important source for enhancing heat tolerance in rice at flowering stage. The SF under high temperature was able to increase at $15 \%$ by qHTSF4.1 (Ye et al. 2015). In a more recent study, 48 stable lines (17 KMR3/Oryza rufipogon introgression lines [KMR3 ILs], 15 Swarna/Oryza nivara ILs [Swarna ILs] along with their parents, Nagina 22 [N22], and its 4 ethyl methanesulfonate induced mutants and 7 varieties) were examined for heat tolerance during dry and wet season (Prasanth et al. 2016). They found out that 18 of 49 SSR markers linked to SF were valid for five traits related to heat tolerance. RM430 and RM210 in dry season and RM229 in wet season were significantly associated with both SF and its heat susceptibility index (HSI) under heat stress. RM430 was also significantly related in both yield per plant (YP) and its HSI in dry season (Prasanth et al. 2016). For an actual application of SSR markers in breeding programs for heat tolerance in rice, a group from Vietnam used RM3735 as one of their six markers to select heat tolerant lines in backcross population at flowering stage (Buu et al. 2013a; Buu et al. 2013b; Lang et al. 2015). Rice breeders can employ these QTLs in pyramiding genes to increase heat tolerance in rice.

\section{BIOTIC STRESSES}

\section{Bacterial blight}

Bacterial leaf blight (BLB) is the most destructive disease, which affects greatly the rice yield loss. Enhancing genetic resistance of rice has proven to be the most effective method of controlling BLB disease (Khan et al. 2014a). To date, at least 38 BLB resistance genes (R genes) (both dominant and recessive) have been identified (Bhasin et al. 2012; Kumar et al. 2012) and designated in a series from $\mathrm{Xa1}$ to $\mathrm{Xa} 38$ (given the prefix Xa for Xanthomonas) (Khan et al. 2014a). There are various DNA markers that have been already developed for many $X a$ genes. Hajira et al. (2016) have developed simple PCR-based functional markers for $x a 13$ and $x a 5$. For $x a 13$, they designed a functional, PCR-based marker, xa13-prom targeting the Indel polymorphism in the promoter of candidate gene, Os $8 N 3$ located on Chr. 8 of rice. For $x a 5$ a multiplex-PCR based functional marker system, named xa5FM, consisting of two sets primer pairs targeting the 2-bp functional nucleotide polymorphism in the exon II of the gene, TFIIA 5 (candidate for $x a 5$ ), has been developed (Hajira et al. 2016). Both $x a 13$-prom and xa5FM can differentiate the resistant and susceptible alleles for $x a 13$ and $x a 5$, respectively in a co-dominant fashion. Using these two functional markers along with the already reported functional, PCR-based marker for Xa21 (pTA248), Hajira et al. (2016) designed a single-tube multiplex PCR based assay for simultaneous detection of all the three major resistance genes and demonstrated the utility of the multiplex marker system in a segregating population.

In the study of Hur et al. (2013), they cloned and sequenced the $X a 3 / x a 3$ gene in the Korean cultivars Hwayeong, Ilmi, and Goun, conferring resistance or susceptibility to bacterial blight. Xa3 is involved in the receptor-like kinases, which contain an extracellular leucine-rich repeat (LRR) and an intracellular serine- 
threonine kinase domain (Hur et al. 2013). The LRR sequence of the LRR-containing $\mathrm{R}$ proteins is the major determinant of pathogen recognition (Dangl and Jones 2001) and showed differences between the resistant and susceptible proteins (Xiang et al. 2006). Thus, the difference in this region could be the SNP region useful for a functional marker. So Hur et al. (2013) designed functional markers (BB3-SR and BB3-RF) in which the 3' terminal nucleotides corresponded to the SNP regions. BB3-SF was located in the upstream promoter region of the $X a 3$ cDNA, and the BB3-RR primer was within exon 1 (Hur et al. 2013). In addition, molecular marker in $\mathrm{Xa} 4$ was used by Luo et al. (2012), as they were developing near-isogenic line carrying both Xa4 and Xa21 loci, they used RM224 (Sun et al. 2003). Further confirming the effective selection of RM224, two homozygous $F_{2}$ individuals were identified with the $\mathrm{Xa} 4$ locus from the 10 $\mathrm{F}_{2}$ plants that were homozygous at the $\mathrm{Xa} 21$ and $\mathrm{Xa} 27$ loci (Luo et al. 2012). Lastly, in introgression of bacterial blight resistance genes $\mathrm{Xa}$ 7, $\mathrm{Xa21}, \mathrm{Xa22}$, and $\mathrm{Xa} 33$ into hybrid rice restorer lines by molecular MAS (Huang et al. 2012), they will adopt the marker for $X a 7$. The resistance gene $\mathrm{Xa} 7$ provides dominant resistance against the pathogen with avirulence (Avr) gene AvrXa7 (Chen et al. 2008). As by-products of fine mapping done by Chen et al. (2008), a number of tightly linked markers for the $X a 7$ gene had been developed; eight markers (RM20573, RM20580, RM20582, RM20595, RM20601, RM20603, RM20608, and RM20612) tightly linked to $\mathrm{Xa} 7$ (genetic distance $<2$ $\mathrm{cM}$ ) can be used in MAB programs. As adopted by Huang et al. (2012) in their introgression work, they used RM20593 to confirm the presence of $X a 7$. Since there are many studies related to improving bacterial blight resistance in rice, the markers suggested here can be used to further shorten the breeding cycles.

\section{Blast}

Rice blast is another devastating disease causing major yield losses globally. Singh et al. (2015) reported that there are more than 100 major blast resistance genes from japonica $(45 \%)$, indica $(51 \%)$, and other (4\%) genotypes that have been identified and documented, and many blast resistant varieties have been developed; however, stronger virulent isolates of rice blast fungus have emerged. So up to now, rice cultivar with broad-spectrum of resistance to highly adaptive virulent isolates/races remains a challenge. In a MAS breeding for blast resistance, $\mathrm{F}_{3}$ population derived from the cross of Pongsu seribu 2 (resistant) and Mahsuri (susceptible) allowed the association of four SSR markers RM413, RM1233, RM8225, and RM5961 to blast resistant genes (Ashkani et al. 2012). Because these markers had high selection accuracy for resistant plant sources, they were suggested to be used in MAS for the resistant gene. Lei et al. (2013) identified and mapped two blast resistance genes, $P i 60(t)$ and $P i 61(t)$, in Chinese rice cultivar 93-11 using $F_{2}$ and $F_{3}$ populations derived from a cross between the susceptible cv. Lijiangxintuanheigu and resistant cv. 93-11. Pi60(t) and Pi61( $t)$ are both embedded in recombination-suppressed regions with several clustered NBS-LRR genes. In addition to these SSR markers, Khan et al. (2014b) suggested gene-based molecular markers for MAS in identifying blast resistance gene in fragrant rice. In their study they found out that the reaction pattern of single-spore isolate of Magnaporthe oryzae to differential varieties showed that Pish, Pi9, Pita-2, and Pita are the effective blast-resistant genes against the tested blast isolates in Bangladesh. After using the four gene-based molecular markers, among the 16 germplasms selected, they found BRRI dhan50, Chinigura, and Bawaibhog that contain more than one target gene and the remaining germplasm contained only one target gene, either Pish or Pita. Recently, Singh et al. (2015) applied 10 SSR markers linked to blast resistance genes (Pi-9, Pi-1, Pi5-( $($ ) , Piz-5, $P i-b, P i-t a, P i 33, P i-27(t), P i t p(t)$, and $\left.P i k^{h}\right)$ in 192 rice accessions to identify which accession contain the most number of resistance genes. They have identified as much as eight blast resistant genes in more than one accession. They also concluded that the linked markers used in their study are well established and effective, thus making them a marker of choice for molecular screening of rice blast resistance genes. We have enlisted blast marker resistant genes for MAS in Table 1 (Jia et al. 2002; Fjellstrom et al. 2004; Hayashi et al. 2006; Qu et al. 2006; Takahashi et al. 2010; Ashkani et al. 2012) 


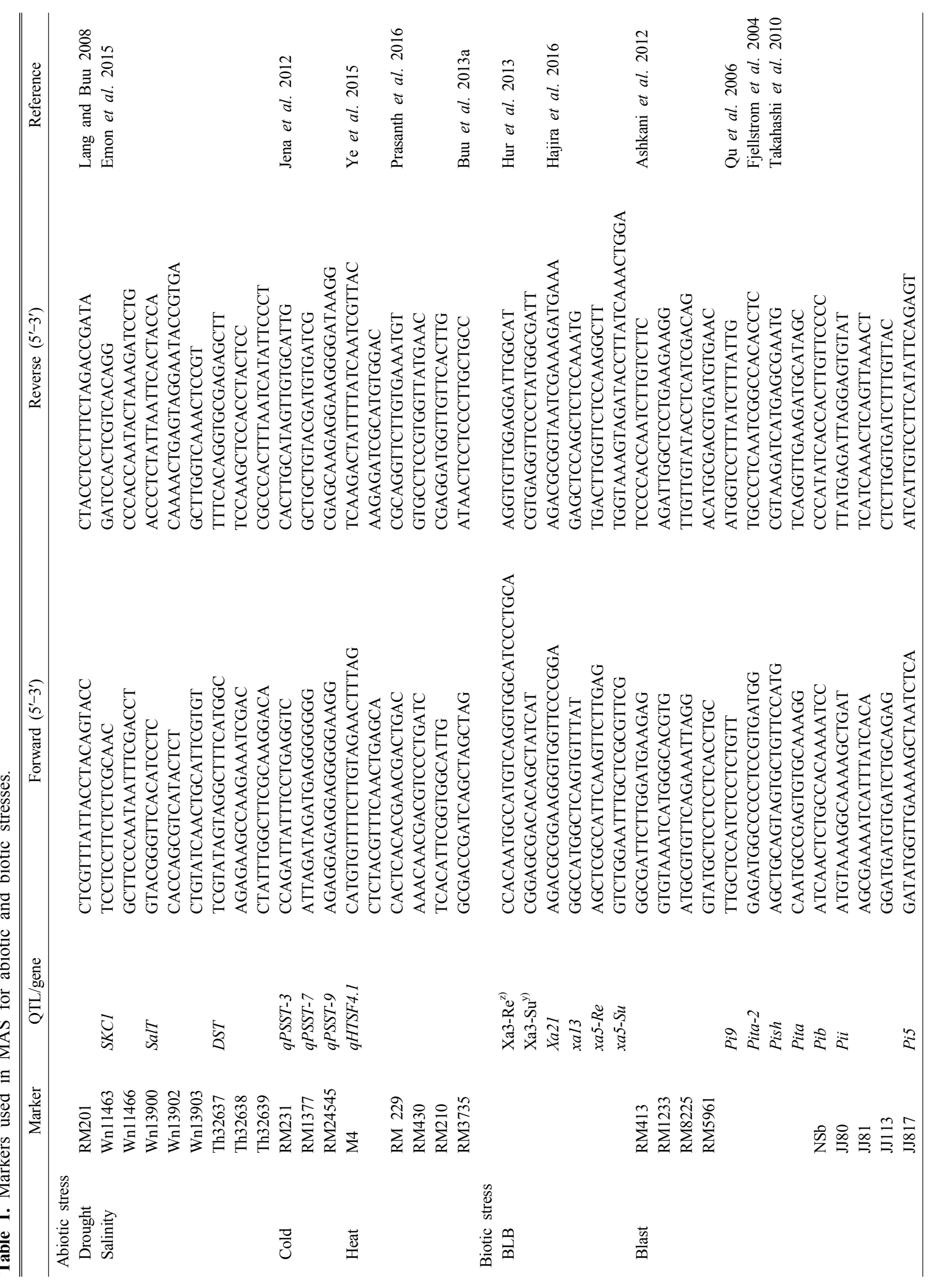




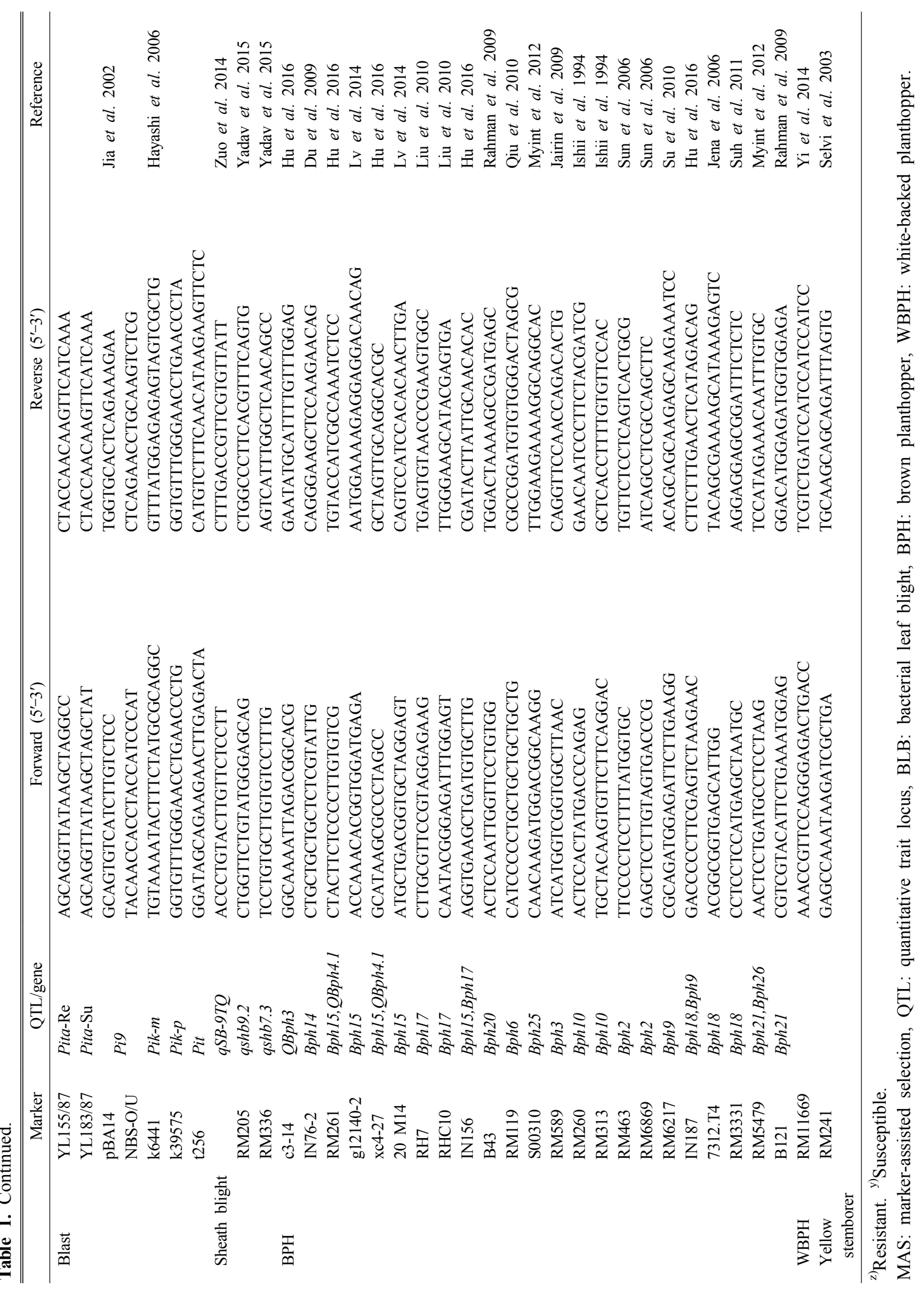




\section{Sheath blight}

In a comprehensive review done by Yellareddygari et al. (2014) on disease and pathogen management approaches in rice sheath blight (ShB), ShB is caused by $R$. solani Kuhn (Teleomorph: Thanatephorus cucumeris [Frank] Donk), and is a destructive disease worldwide that causes significant yield loss and quality degradation. Aside from rice, it can also infect other crops like lettuce, tomato and maize. This fungus is a universal soil saprotrophic and facultative plant parasite. The sclerotia of $R$. solani can survive even in unfavorable conditions. Once the field is set up with plants, the sclerotia will attached to the soaked organ of rice and starts the disease development. To combat almost all kinds of rice diseases, integrated disease management in the field is still highly recommended.

There are about $50 \mathrm{ShB}$ resistance QTLs that have been mapped to all the 12 rice chromosomes and pyramiding of diverse ShB resistance QTLs could help achieve higher levels of resistance to ShB (Yadav et al. 2015). One study showed pyramiding of ShB resistance, $q S B-9 T Q$ and tiller angle TAC1TQ resulted to NILs carrying both QTLs showing more resistance than the NILs containing only one of them (Zuo et al. 2014). Pyramiding major SB resistance QTLs like qShB9-2 (Liu et al. 2013) can give rise to an efficient and effective host resistance. The markers RM215 and RM245 were closely linked to $q S h B 9-2$ and can be used as reliable markers for improving $\mathrm{ShB}$ resistance in rice breeding programs using MAS, for fine mapping, and for positional cloning (Liu et al. 2013). In addition, two SSR markers namely RM336 and RM205 were found to be closely associated with the major QTLs qshb7.3 and $q$ shb9.2 respectively and were attested as well in $\mathrm{BC}_{1} \mathrm{~F}_{2}$ population by bulk segregant analysis approach (Yadav et al. 2015). Lastly, Zeng et al. (2014) constructed the first physical map of previously reported ShB-QTLs, plant height-QTLs, and heading date-QTLs in which this map can be more conveniently used in MAB programs.

\section{Planthoppers}

From the top three major diseases in rice, we go to two of the most serious pests in rice, planthoppers and stem borer. There are two planthoppers that infest rice, BPH and
WBPH. In many areas, BPH frequently occur in numbers large enough to cause complete drying of the crop, but even small populations reduce rice yields. In addition to direct feeding damage, planthoppers are also vectors of most of the currently known rice virus diseases (Pathak and Khan 1994). Just like in abiotic and biotic stresses, the most economical and environment-friendly strategy to control insect pests is to grow genetically resistant rice varieties.

Because of the development of molecular markers (SSR, InDel, SNPs) and functional genomics, the genetic studies of BPH resistance in rice have increased. Currently, more than $30 \mathrm{BPH}$ resistance loci have been reported (Fujita et al. 2013) and four BPH resistance genes (Bph14, Bph26, Bph17, and bph29) have been cloned (Du et al. 2009; Tamura et al. 2014; Liu et al. 2015; Wang et al. 2015). $\mathrm{MAB}$ and conventional breeding have enabled resistance genes to be combined in elite rice varieties to improve $\mathrm{BPH}$ resistance and its durability. Early this year, a review of recent progress on the genetics and molecular breeding of brown plant hopper resistance in rice (Hu et al. 2016) was written and it presents the positional information of BPH-resistance genes and several markers available for MAB (Table 1). In addition, there are reported SSR markers that are specific for BPH biotypes. Shabanimofrad et al. (2015) have concluded that their chi-square analysis showed a good fit to a ratio of 3:1 for the segregation of resistance and susceptibility for biotypes 2 and 3 of BPH. SSR markers RM545, RM401, RM22, RM5953, RM210, RM242, RM217, RM224 and RM1 103 were significantly associated with BPH resistance to biotypes 2 and 3 of BPH in rice $(P \leq 0.01)$. These markers showed high selection accuracy for resistant plant sources with confirmation of resistance effect of about $17 \%$ to $20 \%$ for phenotypic variation and can be used in MAS for the resistant gene (Shabanimofrad et al. 2015).

Relative to BPH, WBPH is less concerned in research, resistance genes $W b p h 7$ and $W b p h 8$ happens to work as well in resistance to BPH (Tan et al. 2004). In addition to these two genes, an ovicidal gene (Ovc) shows a general response to WBPH and BPH (Fujita et al. 2013). According to Fujita et al. (2013), all other WBPH genes have been identified by segregation analysis but have undergone no further genetic analyses and have no iden- 
tified DNA markers. But there is a recent study that applied SSR markers in MAS for WBPH, that study showed 64.9\% of coincidence rate of bioassay and MAB efficiency after using SSR marker RM11669 for WBPH resistance when used in double haploid lines derived from the cross of JSNDH13 with CNDH32 (Yi et al. 2014).

\section{Stem borer}

There are two common stem borers in Asia, yellow stemborer (Scirpophaga incertulas) and white stemborer (S. innotata). In general, stem borers are polyvoltine, meaning they produce several broods in a year, but the number of generations in a year depends on environmental factors, primarily temperature, rainfall, and crop availability (Pathak and Khan 1994). In places having distinct generations, the first generation usually appears when the plants are in seedling stage; the population increases in subsequent broods and the later generations are often the ones that cause serious damage. This is why the borers are more destructive to the late-planted crops, or the second crop where double cropping is observed (Pathak and Khan 1994). The damage of stem borer becomes evident only as deadheart and whitehead, significant losses are also inflicted by larvae that feed within the stem without severing the growing plant parts at the base. Such damage results in reduced plant vigor, fewer tillers, and many unfilled spikelets (Pathak and Khan 1994). Selvi et al. (2002) reported the identification of RAPD markers associated with yellow stemborer resistance and susceptibility, the markers $\mathrm{C}_{1320}$ and $\mathrm{K}_{6695}$ were linked with resistance and $\mathrm{AH}_{5660}$ and $\mathrm{C}_{1300}$ with susceptibility. The markers $\mathrm{K}_{6695}$ and $\mathrm{AH}_{5660}$ were linked to the genes at distances of $12.8 \mathrm{cM}$ and $14.9 \mathrm{cM}$, respectively, their sufficiently closer linkage to the genes regulating the trait and their unambiguous scorability in the resistant and susceptible cultivars were tested. Also, they investigated and described the possibility of screening for yellow stemborer resistance using micro satellite markers. This marker, RM241, located on chromosome 4, was also found to be associated with the trait and is closed to the genes for yellow stemborer resistance (Selvi et al. 2003).

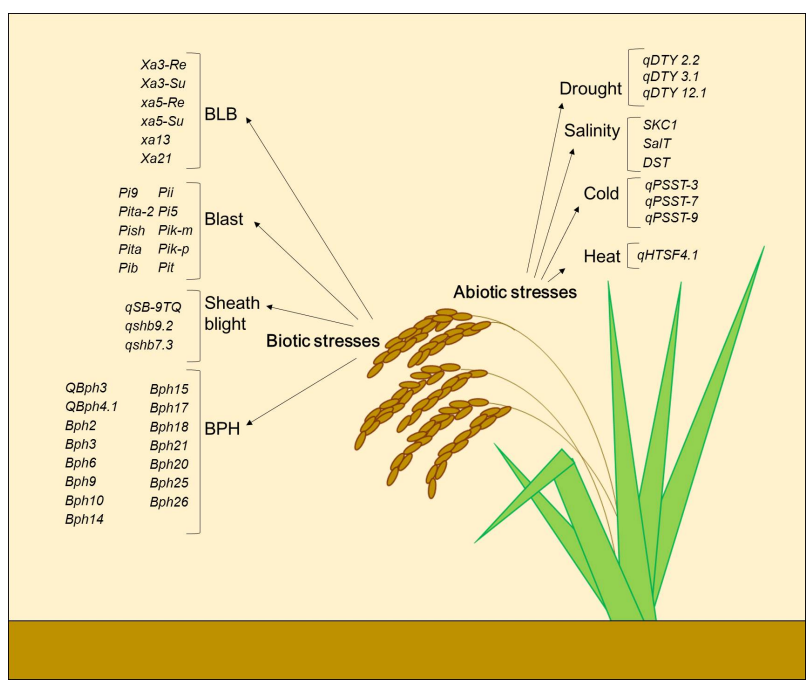

Fig. 1. Summary of QTLs/genes presented here as DNA markers in MAB for abiotic and biotic stress tolerance.

BLB: bacterial leaf blight, BPH: brown planthopper.

\section{CONCLUSION}

In this review, we have summarized some of the recently used DNA-based markers for MAS in abiotic and biotic stress tolerance in rice as shown in Fig. 1. The efficiency of MAS largely depends on the distance between molecular markers and genes/QTLs associated with target traits. The development of useful markers tightly linked to abiotic and biotic stress resistance traits is accomplished by QTL mapping experiments. Generally, the markers are validated in fine mapping studies. MAB greatly increase the efficiency and effectiveness of breeding. By determining and developing DNA markers for target genomic regions, desired individuals possessing particular genes or QTLs can be identified in germplasm collections based on genotyping rather than phenotyping only. Based on the readings made, in any abiotic and biotic stress tolerance, stronger resistance can be attained by pyramiding validated tolerance genes and QTLs. MAS refers to selection by DNA markers linked to QTLs associated target genes. DNA-based genetic markers are recently expected to play an important role in the future of MAB and molecular genetics analysis for development of stress-tolerance and 
disease-resistance in plants through molecular linkage maps. The information of markers for abiotic and biotic tolerant traits gathered here will provide a one-stop read for practical rice breeders and the like to aid in their MAB.

\section{ACKNOWLEDGEMENTS}

This work was supported by Golden Seed Project (No. 2130031-04-4-SB220), Ministry of Agriculture, Food and Rural Affairs (MAFRA), Republic of Korea.

\section{REFERENCES}

Ahmad P, Wani MR, Azooz MM, Tran LSP. 2014. Improvement of crops in the era of climatic changes. Springer New York, New York, NY.

Andersen SB. 2013. Plant breeding from laboratories to fields. InTech, Rijeka. p.47-48.

Ashkani S, Rafii MY, Rusli I, Sariah M, Abdullah SNA, Rahim HA, et al. 2012. SSRs for marker-assisted selection for blast resistance in rice (Oryza sativa L.). Plant Mol. Biol. Rep. 30: 79-86.

Ashraf M, Akram NA, Mehboob-Ur-Rahman, Foolad MR. 2012. Marker-assisted selection in plant breeding for salinity tolerance. Methods Mol. Biol. 913: 305-333.

Bhasin H, Bhatia D, Raghuvanshi S, Lore JS, Sahi GK, Kaur $\mathrm{B}$, et al. 2012. New PCR-based sequence-tagged site marker for bacterial blight resistance gene $\mathrm{Xa} 38$ of rice. Mol. Breed. 30: 607-611.

Bonnecarrère V, Quero G, Monteverde E, Rosas J, Pérez de Vida F, Cruz M, et al. 2014. Candidate gene markers associated with cold tolerance in vegetative stage of rice (Oryza sativa L.). Euphytica 203: 385-398.

Boyer JS. 1982. Plant productivity and environment. Science 218: 443-448.

Buu CB, Thu HP, Tam B, Nhien T, Hieu N, Phuoc N, et al. 2013a. Quantitative trait loci associated with heat tolerance in rice (Oryza sativa L.). Plant Breed. Biotech. 2: $14-24$.

Buu BC, Thu Ha PT, Tam BP, Nha CT, Lang NT. 2013b. Study on genetic variation of heat tolerance trait in BC population of rice (Oryza sativa L.). J. Agric. Rural Dev. 2: $10-15$.
Chen S, Huang Z, Zeng L, Yang J, Liu Q, Zhu X. 2008. High-resolution mapping and gene prediction of Xanthomonas oryzae pv. oryzae resistance gene Xa7. Mol. Breed. 22: 433-441.

Chen W, Li W. 2005. Mapping of QTL conferring cold tolerance at early seedling stage of rice by molecular markers. Plant Sci. J. 23: 116-120.

Climate Central. 2016. 2016 Is Blowing Away Global Heat Records [Internet]. Climate Central, Princeton, NJ. [cited 2016 Aug 9]. Available from: http://www.climatecentral.org/gallery/graphics/2016-is-blowing-away-global-h eat-records.

Dangl JL, Jones JD. 2001. Plant pathogens and integrated defence responses to infection. Nature 411: 826-833.

de los Reyes BG, Morsy M, Gibbons J, Varma TS, Antoine W, McGrath JM, et al. 2003. A snapshot of the low temperature stress transcriptome of developing rice seedlings (Oryza sativa L.) via ESTs from subtracted cDNA library. Theor. Appl. Genet. 107: 1071-1082.

Du B, Zhang W, Liu B, Hu J, Wei Z, Shi Z, et al. 2009. Identification and characterization of Bph14, a gene conferring resistance to brown planthopper in rice. Proc. Natl. Acad. Sci. U.S.A. 106: 22163-22168.

Emon RM, Islam MM, Halder J, Fan Y. 2015. Genetic diversity and association mapping for salinity tolerance in Bangladeshi rice landraces. Crop J. 3: 440-444.

Fjellstrom R, Conaway-Bormans CA, McClung AM, Marchetti MA, Shank AR, Park WD. 2004. Development of DNA markers suitable for marker assisted selection of three $P i$ genes conferring resistance to multiple Pyricularia grisea pathotypes. Crop Sci. 44: 1790-1798

Fujita D, Kohli A, Horgan FG. 2013. Rice resistance to planthoppers and leafhoppers. Crit. Rev. Plant Sci. 32: 162-191.

Gomez SR. 2013. Abiotic and biotic stress in plants, p.1-20. In: G.R. Rout, A.B. Das (eds.). Molecular stress physiology of plants. Springer, New Delhi.

Hajira SK, Sundaram RM, Laha GS, Yugander A, Balachandran SM, Viraktamath BC, et al. 2016. A single-tube, functional marker-based multiplex PCR assay for simultaneous detection of major bacterial blight resistance genes Xa21, xa13 and xa5 in rice. Rice Sci. 23: 144-151.

Harvey F. 2015. Everything you need to know about the Paris climate summit and UN talks [Internet]. The Guardian, 
London. [Accessed 2016 Aug 6]. Available from: https://www.theguardian.com/environment/2015/jun/02/ everything-you-need-to-know-about-the-paris-climate-s ummit-and-un-talks.

Hayashi K, Yoshida H, Ashikawa I. 2006. Development of PCR-based allele-specific and InDel marker sets for nine rice blast resistance genes. Theor. Appl. Genet. 113: 251-260.

Huang B, Xu JY, Hou MS, Ali J, Mou TM. 2012. Introgression of bacterial blight resistance genes $\mathrm{Xa}, \mathrm{Xa21}$, $X a 22$ and $X a 23$ into hybrid rice restorer lines by molecular marker-assisted selection. Euphytica 187: 449-459.

Hu J, Xiao C, He Y. 2016. Recent progress on the genetics and molecular breeding of brown planthopper resistance in rice. Rice (N Y) 9: 30.

Hur YJ, Jeung JU, Kim SY, Park HS, Cho JH, Lee JY, et al. 2013. Functional markers for bacterial blight resistance gene Xa3 in rice. Mol. Breed. 31: 981-985.

Ishii T, Brar DS, Multani DS, Khush GS. 1994. Molecular tagging of genes for brown planthopper resistance and earliness introgressed from Oryza australiensis into cultivated rice, O. sativa. Genome 37: 217-221.

Jairin J, Teangdeerith S, Leelagud P, Kothcharerk J, Sansen K, Yic M, et al. 2009. Development of rice introgression lines with brown planthopper resistance and KDML105 grain quality characteristics through marker-assisted selection. Field Crops Res. 110: 263-271.

Jena KK, Kim SM, Suh JP, Yang CI, Kim YG. 2012. Identification of cold-tolerant breeding lines by quantitative trait loci associated with cold tolerance in rice. Crop Sci. 52: 517-523.

Jena KK, Jeung JU, Lee JH, Choi HC, Brar DS. 2006. Highresolution mapping of a new brown planthopper (BPH) resistance gene, Bph18(t), and marker-assisted selection for BPH resistance in rice (Oryza sativa L.). Theor. Appl. Genet. 112: 288-297.

Jia Y, Wang Z, Singh P. 2002. Development of dominant rice blast Pi-ta resistance gene markers. Crop Sci. 42: 2145 2149.

Jiang Y, Cai Z, Xie W, Long T, Yu H, Zhang Q. 2012. Rice functional genomics research: progress and implications for crop genetic improvement. Biotechnol. Adv. 30: 1059-1070.

Khan MA, Naeem M, Iqbal M. 2014a. Breeding approaches for bacterial leaf blight resistance in rice (Oryza sativa
L.), current status and future directions. Eur. J. Plant Pathol. 139: 27-37.

Khan MA, Sen PP, Bhuiyan R, Kabir E, Chowdhury AK, Fukuta Y, et al. 2014b. Phenotypic screening and molecular analysis of blast resistance in fragrant rice for marker assisted selection. C. R. Biol. 337: 318-324.

Kottearachchi NS. 2013. Utility of DNA markers in rice breeding. Eur. Int. J. Sci. Technol. 2: 111-122.

Kramer PJ, Boyer JS. 1995. Water relations of plants and soils. Academic Press, New York, NY.

Kumar PN, Sujatha K, Laha GS, Rao KS, Mishra B, Viraktamath BC, et al. 2012. Identification and fine-mapping of Xa33, a novel gene for resistance to Xanthomonas oryzae pv. oryzae. Phytopathology 102: 222-228.

Lateef D. 2015. DNA marker technologies in plants and applications for crop improvements. J. Biosci. Med. 3: 7-18.

Lang NT, Ha PTT, Tru PC, Toan TB, Buu BC, Cho YC. 2015. Breeding for heat tolerance rice based on marker-assisted backcrossing in Vietnam. Plant Breed. Biotech. 3: 274-281.

Lang NF, Buu BC. 2008. Fine mapping for drought tolerance in rice (Oryza sativa L.). Omonrice 16: 9-15.

Lei C, Hao K, Yang Y, Ma J, Wang S, Wang J, et al. 2013. Identification and fine mapping of two blast resistance genes in rice cultivar 93-11. Crop J. 1: 2-14.

Linh le H, Linh TH, Xuan TD, Ham le H, Ismail AM, Khanh TD. 2012. Molecular breeding to improve salt tolerance of rice (Oryza sativa L.) in the Red River Delta of Vietnam. Int. J. Plant Genom. 2012: 949038.

Liu X, Yang Z, Gao G, Lin Y, Zhu X, Yu J, et al. 2010. Development of Bt rice by molecular marker-assisted selection and assays for insect-resistance. Mol. Plant Breed. 1: 1-6.

Liu G, Jia Y, McClung A, Oard JH, Lee FN, Correll JC. 2013. Confirming QTLs and finding additional loci responsible for resistance to rice sheath blight disease. Plant Dis. 97: 113-117.

Liu Y, Wu H, Chen H, Liu Y, He J, Kang H, et al. 2015. A gene cluster encoding lectin receptor kinases confers broad-spectrum and durable insect resistance in rice. Nat. Biotechnol. 33: 301-305.

Luo Y, Sangha J, Wang S, Li Z, Yang J, Yin Z. 2012. Marker-assisted breeding of Xa4, Xa21 and Xa27 in the 
restorer lines of hybrid rice for broad-spectrum and enhanced disease resistance to bacterial blight. Mol. Breed. 30: 1601-1610.

Lv W, Du B, Shangguan X, Zhao Y, Pan Y, Zhu L, et al. 2014. $\mathrm{BAC}$ and RNA sequencing reveal the brown planthopper resistance gene $\mathrm{BPH} 15$ in a recombination cold spot that mediates a unique defense mechanism. BMC Genomics 15: 674.

Maclean JL, Dawe DC, Hardy B, Hettel GP. 2002. Rice almanac: source book for the most important economic activity on earth. 3rd ed. CABI Publishing, Wallingford, UK.

Morris M, Dreher K, Ribaut JM, Khairallah M. 2003. Money matters (II): costs of maize inbred line conversion schemes at CIMMYT using conventional and markerassisted selection. Mol. Breed. 11: 235-247.

Mohler V, Singrün C. 2004. General considerations: markerassisted selection, p.305-317. In: H. Lörz, G. Wenzel (eds.). Molecular marker systems in plant breeding and crop improvement. Springer Berlin Heidelberg, Heidelberg.

Myint KK, Fujita D, Matsumura M, Sonoda T, Yoshimura A, Yasui H. 2012. Mapping and pyramiding of two major genes for resistance to the brown planthopper (Nilaparvata lugens [Stål]) in the rice cultivar ADR52. Theor. Appl. Genet. 124: 495-504.

Nejad G, Arzani A, Rezai AM, Singh RK, Gregorio GB. 2008. Assessment of rice genotypes for salt tolerance using microsatellite markers associated with the saltol QTL. Afr. J. Biotechnol. 7: 730-736.

Outcomes of the U.N. Climate Change Conference in Paris. 2015. In 21st Session of the Conference of the Parties to the United Nations Framework Convention on Climate Change (COP 21) [Internet]. Center for Climate and Energy Solutions, Arlington, VA [cited 2015 Dec]. Available from: http://www.c2es.org/international/negotiations/cop21-paris/ summary.

Pareek A, Singla SL, Grover A. 1995. Immunological evidence for accumulation of two high-molecular-weight (104 and $90 \mathrm{kDa}$ ) HSPs in response to different stresses in rice and in response to high temperature stress in diverse plant genera. Plant Mol. Biol. 29: 293-301.

Pathak MD, Khan ZR. 1994. Insect pests of rice. 2nd ed. International Rice Research Institute, Philippines.

Prasanth VV, Basava KR, Babu MS, V G N VT, Devi SJ, Mangrauthia SK, et al. 2016. Field level evaluation of rice introgression lines for heat tolerance and validation of markers linked to spikelet fertility. Physiol. Mol. Biol. Plants 22: 179-192.

Qiu Y, Guo J, Jing S, Zhu L, He G. 2010. High-resolution mapping of the brown planthopper resistance gene Bph6 in rice and characterizing its resistance in the 9311 and Nipponbare near isogenic backgrounds. Theor. Appl. Genet. 121:1601-1611.

Qu S, Liu G, Zhou B, Bellizzi M, Zeng L, Dai L, et al. 2006. The broad-spectrum blast resistance gene $P i 9$ encodes a nucleotide-binding site-leucine-rich repeat protein and is a member of a multigene family in rice. Genetics 172: 1901-1914.

Rahman ML, Jiang W, Chu SH, Qiao Y, Ham TH, Woo MO, et al. 2009. High-resolution mapping of two rice brown planthopper resistance genes, Bph20(t) and Bph21(t), originating from Oryza minuta. Theor. Appl. Genet. 119: 1237-1246.

Ribaut JM, Hoisington D. 1998. Marker-assisted selection: new tools and strategies. Trends Plant Sci. 3: 236-239.

Robinson P, Holme J. 2011. KASP Version 4.0 SNP Genotyping Manual [Internet]. KBio Science. [cited 2011 May]. Available from: http://www.cerealsdb.uk.net/cerealgenomics/ CerealsDBNEW/PDFs/KASP_SNP_Genotyping_Manual.pdf. Salekdeh GH, Siopongco J, Wade LJ, Ghareyazie B, Bennett J. 2002. A proteomic approach to analyzing drought- and salt responsiveness in rice. Field Crops Res. 76: 199-219.

Salunkhe AS, Poornima R, Prince KS, Kanagaraj P, Sheeba JA, Amudha K, et al. 2011. Fine mapping QTL for drought resistance traits in rice (Oryza sativa L.) using bulk segregant analysis. Mol. Biotechnol. 49: 90-95.

Sasaki T, Burr B. 2000. International Rice Genome Sequencing Project: the effort to completely sequence the rice genome. Curr. Opin. Plant Biol. 3: 138-141.

Selvi A, Shanmugasundaram P, Mohankumar S, Raja JAJ. 2002. Molecular markers for yellow stem borer, Scirpophaga incertulas (Walker) resistance in rice. Euphytica 124: 371-377.

Selvi A, Shanmugasundaram P, Mohankumar S, Raja JAJ. 2003. Molecular marker association for yellow stem borer resistance in rice. Mol. Biol. 3\&4: 117-124.

Shabanimofrad M, Yusop M, Ashkani S, Musa M, Adam NA, Haifa I, et al. 2015. Marker-assisted selection for rice brown planthopper (Nilaparvata lugens) resistance using linked SSR markers. Turk. J. Biol. 39: 666-673. 
Shamsudin NA, Swamy BP, Ratnam W, Sta Cruz MT, Raman A, Kumar A. 2016. Marker assisted pyramiding of drought yield QTLs into a popular Malaysian rice cultivar, MR219. BMC Genet. 17: 30.

Singh AK, Singh PK, Arya M, Singh NK, Singh US. 2015. Molecular screening of blast resistance genes in rice using SSR markers. Plant Pathol. J. 31: 12-24.

Su C, Xie J, Wang X, Peng Y. 2010. Integrated structure and event-specific real-time detection of transgenic $c r y 1 A c / S C K$ rice Kefeng 6. Eur. Food Res. Technol. 232: 351-359.

Suh JP, Yang SJ, Jeung JU, Pamplona A, Kim JJ, Lee JH, et al. 2011. Development of elite breeding lines conferring Bph18 gene-derived resistance to brown planthopper (BPH) by marker-assisted selection and genome-wide background analysis in japonica rice (Oryza sativa L.). Field Crops Res. 120: 215-222.

Sun X, Yang Z, Wang S, Zhang Q. 2003. Identification of a 47-kb DNA fragment containing $\mathrm{Xa4}$, a locus for bacterial blight resistance in rice. Theor. Appl. Genet. 106: 683-687.

Sun LH, Wang CM, Su CC, Liu YQ, Zhai HQ, Wan JM. 2006. Mapping and marker-assisted selection of a brown planthopper resistance gene bph2 in rice (Oryza sativa L.). Yi Chuan Xue Bao 33: 717-723.

Takahashi A, Hayashi N, Miyao A, Hirochika H. 2010. Unique features of the rice blast resistance Pish locus revealed by large scale retrotransposon-tagging. BMC Plant Biol. 10: 175.

Tamura Y, Hattori M, Yoshioka H, Yoshioka M, Takahashi A, Wu J, et al. 2014. Map-based cloning and characterization of a brown planthopper resistance gene BPH26 from Oryza sativa L. ssp. indica cultivar ADR52. Sci. Rep. 4: 5872.

Tan GX, Weng QM, Ren X, Huang Z, Zhu LL, He GC. 2004. Two whitebacked planthopper resistance genes in rice share the same loci with those for brown planthopper resistance. Heredity (Edinb.) 92: 212-217.

Tester M, Bacic A. 2005. Abiotic stress tolerance in grasses. From model plants to crop plants. Plant Physiol. 137: 791-793.

Thitisaksakul M, Tananuwong K, Shoemaker CF, Chun A, Tanadul OU, Labavitch JM, et al. 2015. Effects of timing and severity of salinity stress on rice (Oryza sativa L.) yield, grain composition, and starch functionality. J. Agric. Food Chem. 63: 2296-2304.

Uga Y, Okuno K, Yano M. 2011. Drol, a major QTL involved in deep rooting of rice under upland field conditions. J. Exp. Bot. 62: 2485-2494.

Wang Y, Cao L, Zhang Y, Cao C, Liu F, Huang F, et al. 2015. Map-based cloning and characterization of $\mathrm{BPH}_{2} 9$, a B3 domain-containing recessive gene conferring brown planthopper resistance in rice. J. Exp. Bot. 66: 6035-6045.

Wang W, Vinocur B, Altman A. 2003. Plant responses to drought, salinity and extreme temperatures: towards genetic engineering for stress tolerance. Planta 218: 1-14.

Xiang Y, Cao Y, Xu C, Li X, Wang S. 2006. Xa3, conferring resistance for rice bacterial blight and encoding a receptor kinase-like protein, is the same as Xa26. Theor. Appl. Genet. 113: 1347-1355.

Yadav S, Anuradha G, Kumar RR, Vemireddy LR, Sudhakar R, Donempudi K, et al. 2015. Identification of QTLs and possible candidate genes conferring sheath blight resistance in rice (Oryza sativa L.). SpringerPlus 4: 175.

Yellareddygari SKR, Meddy MS, Kloepper JW, Lawrence KS, Fadamiro H. 2014. Rice sheath blight: a review of disease and pathogen management approaches. J. Plant Pathol. Microbiol. 5: 241

Yi G, Lee HS, Kim KM. 2014. Improved marker-assisted selection efficiency of multi-resistance in doubled haploid rice plants. Euphytica 203: 421-428.

Ye C, Tenorio FA, Argayoso MA, Laza MA, Koh HJ, Redoña $\mathrm{ED}$, et al. 2015. Identifying and confirming quantitative trait loci associated with heat tolerance at flowering stage in different rice populations. BMC Genet. 16: 41.

Zeng Y, Ji Z, Yang C. 2014. The way to a more precise sheath blight resistance QTL in rice. Euphytica 203: 33-45.

Zhang Q, Chen Q, Wang S, Hong Y, Wang Z. 2014. Rice and cold stress: methods for its evaluation and summary of cold tolerance-related quantitative trait loci. Rice (N Y) 7: 24

Zuo S, Zhang Y, Chen Z, Jiang W, Feng M, Pan X. 2014. Improvement of rice resistance to sheath blight by pyramiding QTLs conditioning disease resistance and tiller angle. Rice Sci. 21: 318-326. 